\title{
ELS COMPONENTS DE LA PASSIVA. UNA PERSPECTIVA DIACRÒNICA*
}

\author{
THE COMPONENTS OF THE PASSIVE. \\ A DIACHRONIC PERSPECTIVE
}

\author{
Anna Bartra-Kaufmann \\ Universitat Autònoma de Barcelona \\ anna.bartra@uab.cat
}

Resum: En aquest article es defensa, a partir d'unes dades del català antic, que "passiva» és un terme paraigua sense capacitat explicativa i que no es pot parlar d'una construcció passiva, sinó de la interacció de fenòmens com l'aspecte verbal i la legitimació de l'argument intern, en definitiva, de les propietats de les diverses categories funcionals presents a l'estructura. La passiva és un epifenomen. Aquesta aproximació construccionista i estrictament composicional permet superar les clàssiques restriccions sobre les passives establertes en funció de la naturalesa lèxica del predicat. S'hi argumenta que les oracions anomenades passives perifràstiques de les llengües romàniques són oracions reduïdes que requereixen d'un verb lleuger (ser o estar) per legitimar la seva temporalitat i la seva independència discursiva. Apuntem també, de manera temptativa, que la teoria de fases del programa minimista ofereix una via d'explicació molt prometedora de les dues capes de les oracions passives: l'aspectual i la temporal-discursiva. L'enfocament diacrònic permet veure la influència del sistema llatí: el paradigma perfectiu, d'una banda, i la morfologia específica de les formes sintètiques, de l'altra.

Paraules clau: passiva, sintaxi diacrònica, aspecte, categories funcionals, estructura lèxica.

$\left(^{*}\right)$ Aquest treball ha estat possible gràcies als ajuts del Ministerio de Economía y Competitividad FFI20I22-29440-Co3-03 i de la Generalitat de Catalunya AGAUR SGR2OI4-IOI3.

Agraeixo a Jaume Mateu, M. Carmen Picallo, Gemma Rigau i dos revisors anònims els seus comentaris, així com a Víctor Acedo-Matellán i Manuel Pérez Saldanya observacions en la presentació feta a l'Ibero-Romance Linguistics Fest a la University of Cambridge el 24 de març de 2015 , que contenia algunes de qüestions que es presenten —reelaborades - aquí. La responsabilitat del que s'hi diu és solament meva. 
Anna Bartra-Kaufmann

Els components de la passiva. Una perspectiva diacrònica

Abstract: In this paper we argue that "passive sentence» is a cover term with no empirical import or explanatory interest, an epiphenomenon. The properties of passives are derived from the interaction of the formal properties of the functional categories involved. This strictly compositional and constructionist view allows us to gain explanatory adequacy compared to previous approaches based on the properties of individual predicates. Our leading idea is that Romance passives are in fact participial absolute constructions with a light verb (ésser or estar) merged into the structure to license its temporal and discourse features. Specifically, two layers are relevant in passive sentences: a lower area headed by an Aspect projection and a higher one in the T-C system. We tentatively explore the possibility that phase theory could account for these facts. Addressing the topic from a diachronic perspective, further support to our view comes from the discussion of the crucial the role of the perfective system and the passivizing morphology of Latin.

Key words: passive sentences, diachronic syntax, aspect, functional categories, lexical structure.

\section{es es es}

Saepe quidem Grammatici, numquam tamen ita egregie delirarunt quam in uerborum passiuorum deliramentis tradendis. («Los gramáticos han delirado muchas veces, pero nunca tan extraordinariamente como en sus locas doctrinas sobre los verbos pasivos.»)

Francisco Sánchez de las Brozas (El Brocense), Minerva o De Causis Linguae Latinae

\section{INTRODUCCIÓ: PLANTEJAMENT I OBJECTIUS}

L’objectiu d'aquest treball és avançar en el camí cap a la caracterització i l'anàlisi de les oracions passives perifràstiques (ser + participi passat), tot posant el focus sobre les aparents diferències entre les restriccions que presenten les oracions passives perifràstiques del català contemporani $(\mathrm{CC}) \mathrm{i}$ les del català antic $(\mathrm{CA})$ per tal de caracteritzar les oracions passives del català en general. Volem mostrar, d'una banda, que les diferències entre els dos estadis de llengua són menors del que aparenten $i$, de l'altra, que es poden reduir a les propietats de les categories funcionals implicades en les oracions passives perifràstiques. Plantegem la hipòtesi que les passives perifràstiques del català antic són encara deutores de les propietats de l'arquitectura funcional de les oracions perfectives del llatí.

Adoptem la visió segons la qual una oració passiva és una estructura construïda composicionalment i no un tipus d'oració globalment relacionada amb una oració 
activa. ${ }^{1}$ En la línia iniciada a Chomsky (I99I) considerem que etiquetes del tipus "oració passiva" o "oració relativa" són útils com a abreviatures, però són epifenòmens sense validesa científica, i que les propietats de les construccions lingüístiques es deriven de la interacció de diversos mecanismes i propietats del sistema computacional. ${ }^{2}$

Defensem que les construccions passives són estructures participials — similars a les construccions absolutes_ — i que el participi passat o passiu (d'ara endavant, PP) és el responsable de l'estructura predicativa, mentre que els nodes $\mathrm{S} v$ i SVeu legitimen el valor esdevenimental i agentiu i $\mathrm{T}$ —en connexió amb C- és el responsable de la temporalitat, connectada amb l'auxiliar ser. En la línia de les teories neoconstruccionistes, assumim que tots elements lèxics presents en una estructura participen en la construcció del significat del predicat, de manera que no es pot parlar estrictament, per exemple, de «verbs (a)tèlics», sinó de «construccions (a)tèliques». Les propietats de les construccions no són una funció dels verbs, sinó de les diverses categories presents a l'estructura. En el cas de la passiva, els elements crucials que interaccionen són la

I. Els filòlegs clàssics han dubtat des de ben antic de l'existència de les passives com a construccions independents, pel fet que no n'existeix una morfologia específica. Ja Nebrija remarca que «El latín tiene tres bozes: activa, verbo impersonal, passiva; el castellano no tiene sino sola el activa. El verbo impersonal suple lo por las terceras personas del plural del verbo activo del mesmo tiempo et modo, o por las terceras personas del singular, haziendo en ellas reciprocación et retorno con este pronombre "se"; et assí por lo que en el latín dizen "curritur, currebatur", nos otros dezimos "corren, corrían", o "córrese, corríase"; et assí por todo lo restante de la conjugación. La passiva suple la por este verbo "so, eres" et el participio del tiempo passado de la passiva mesma, assí como lo haze el latín en los tiempos que faltan en la mesma passiva; assí que por lo que el latín dize "amor, amabar, amabor", nos otros dezimos "io so amado, io era amado, io seré amado", por rodeo deste verbo "so, eres" et deste participio "amado"; et assí de todos los otros tiempos.» Altres autors destaquen el poc ús que se’n fa en el romanç primitiu: «Il est évident que la crise n’était pas simplement une crise morphologique: ce n’était pas le passif synthétique [...] qui était en cause, mais le passif en tant que "voix", plus exactement la construction passive de la phrase» (Herman 2002).

2. Els registres existents mostren que hi ha una mínima diferència quantitativa entre llengües amb construcció passiva i sense a favor d'aquestes darreres. Les dades són de <http://wals.info/feature/IO7A\#4/40.3I/4I.79>. En aquesta mateixa obra es donen les cinc característiques definitòries de les construccions passives que han guiat la classificació:

i. it contrasts with another construction, the active;

ii. the subject of the active corresponds to a non-obligatory oblique phrase of the passive or is not overtly expressed;

iii. the subject of the passive, if there is one, corresponds to the direct object of the active;

iv. the construction is pragmatically restricted relative to the active;

iv. the construction displays some special morphological marking of the verb.

Tot i la condició (v), es diferencien al WALS les oracions passives sintètiques (llatí, polonès), de les analítiques (català, anglès). Només cal mostrar que la morfologia de les passives analítiques romàniques no és específica de la passiva per dubtar que compleixin tots els requisits.

Caplletra 61 (Tardor, 2016), pp. 295-327 
perfectivitat, codificada en el participi passat (PP), l'agentivitat, codificada en el SVeu ${ }^{3}$ i la temporalitat, codificada en el ST. ${ }^{4}$

El treball està organitzat de la forma següent. A la secció 2 presentem el tractament estàndard de les restriccions lexicosemàntiques $\mathrm{i}$ temporals que afecten les oracions passives perifràstiques. A la secció 3 presentem una primera mostra de les dades del CA que poden resultar problemàtiques per a aquestes explicacions i fem un breu repàs de les nostres assumpcions sobre el canvi lingüístic. A la secció 4 mostrem amb més detall les dades aparentment problemàtiques, n'analitzem les propietats $\mathrm{i}$ en presentem una primera explicació. A la secció 5 presentem una possible explicació formal unificadora. La secció 6 conclou.

\section{LES RESTRICCIONS DE LA PASSIVA PERIFRÀSTICA}

Les construccions passives perifràstiques presenten diverses restriccions en algunes llengües romàniques occidentals, i concretament en català. Chomsky (1965: IO3-IO4), amb la regla de reescriptura (I), fa el primer intent dins el model generatiu de restringir l'aplicació de la regla de passiva i excloure'n els predicats estatius no agentius - els que no admeten modificadors de manera:

(I) Manner $\rightarrow$ bynPassive

En el model de Principis i Paràmetres es fa un salt endavant important en distingir les passives adjectives de les verbals a partir de l'especificació de trets del PP:

(2) Passives verbals/adjectivals:

Taula I: Chomsky I98I

\begin{tabular}{|l|c|c|}
\hline Tret & PPVerbal/Sintàctic & PPAdjectival/Lèxic \\
\hline $\mathrm{N}$ & --- & + \\
\hline $\mathrm{V}$ & + & + \\
\hline
\end{tabular}

3. De moment, suposem que SVeu és l'encarregat de legitimar l'argument extern i en les passives també s'hi legitima el SPAgent (Kratzer 1996; Collins 2005; Alexiadou 2014).

4. Debatrem més endavant la necessitat d'un node $\mathrm{SAsp}_{\text {Extern }}$. 
Les passives lèxiques o adjectives són generades a la base mentre que les sintàctiques són el resultat de l'aplicació de la regla Traslladeu- $\alpha$, motivada per requeriments de Cas i les condicions de la Teoria- $\theta$. En aquest model s'inicia l'atomització de les construccions — ara considerades epifenòmens - explicades com a resultat de la interacció de principis generals independentment motivats, per a les passives els de (3): ${ }^{5}$

(3) (I) $[\mathrm{SN}, \mathrm{O}]$ no rep un paper- $\theta$;

(II) $[\mathrm{SN}, \mathrm{SV}]$ no rep Cas dins SV.

(Chomsky 198I: 124)

(3II) s’explica per la neutralització dels trets del PP (que no és [-N] i, per tant, no pot assignar Cas), però encara cal explicar el fet que (3I) i (3II) estiguin en correlació. Burzio (I98I) estableix la generalització descriptiva de (4):

(4) Generalització de Burzio

Un element assigna Cas a un $S N$ regit si i només si assigna un paper- $\theta$ al seu subjecte.

A (4), cal sumar-hi (5):

(5) HUAPT (Hipòtesi de la uniformitat en l'assignació de paper temàtic)

Les relacions temàtiques idèntiques entre els ítems lèxics es representen per relacions estructurals idèntiques al nivell de l'estructura profunda. ${ }^{6}$

Les generalitzacions de (3), (4) i (5) estan independentment motivades, però en el cas de les construccions passives, conflueixen a fer-ne un tractament coincident amb la visió tradicional segons la qual la construcció passiva és el resultat d'aplicar modificacions morfològiques i trasllats a una construcció activa. Dins aquest model, Jaeggli (1986) i Baker et alii (1989) justifiquen la segona part de la correlació de Burzio pel fet que el sufix del PP absorbeix el paper $\theta$ extern del V, essent el paper- $\theta$ de l'argument extern l'únic paper $\theta$ que no està associat a un tret de subcategorització específic.

5. Aquestes propietats són comunes a altres construccions, com per exemple les construccions d'elevació. En l'oració Aquesta noia sembla trista, el SN aquesta noia no pot rebre Cas dins la projecció on rep paper- $\theta$ de l'adjectiu trista, ja que no hi ha cap node $\mathrm{T}$ i per això es desplaça a la frase matriu, on $\mathrm{T}$ li assigna Nominatiu sota recció.

6. UTAH(Uniformity of Theta Assignment Hypothesis): «Identical thematic relationships between items are represented by identical structural relationships between these items at the level of D-structure» (Baker 1988: 46)..

Caplletra 61 (Tardor, 2016), pp. 295-327 
La coincidència de paper- $\theta$ entre el subjecte de l'activa i el SP agent de la passiva es dóna perquè en la passiva el SP introduït per per està seleccionat pel morfema del PP.

En aquest marc «clàssic», tot i que s'avança en no proposar una regla de passivització ad hoc, l'aplicació «cega» de les regles no permet explicar les diferències de gramaticalitat inter i intralingüística a l'hora de passivitzar alguns verbs transitius. La recerca en semàntica lèxica, estructura argumental i aspecte verbal — tant lèxic com gramatical - ha mostrat que el concepte de transitivitat és un paraigua que aixopluga relacions diverses entre els predicats i els seus arguments i ha permès una classificació molt més fina dels diversos tipus de predicats i de les construccions que els contenen. ${ }^{7}$

La separació de les propietats de temps i d'aspecte que es codifiquen en categories funcionals respecte de les propietats derivades de l'estructura argumental i la dimensió aspectual interna del predicat permet començar a besllumar la complexitat de les relacions implicades en la (a)gramaticalitat de les oracions passives. ${ }^{8}$ Les seqüencies recollides a (6) - (II) —adaptades de Mendikoetxea (I999)— són anòmales com a passives agentives: ${ }^{9}$

(6) \#La porta és oberta (*pel porter)

(7) * L'ostatge és assassinat

(8) *Són construïdes les cases pel promotor

(9) *El tret era disparat

(Iо) *Tres mil euros van ser costats per l'aparell

(II) * La casa era envoltada pels xiprers

Les generalitzacions de Mendikotexea són a la taula següent:

7. No podem fer referència a l'amplíssima bibliografia que hi ha sobre aquestes qüestions. Esmentem només Hale \& Keyser (I993; 2002); Levin \& Rappaport (I995); Pustejovsky (I99I); Ramchand (2008).

8. Les restriccions aspectuals i temporals sobre les oracions passives perifràstiques ja van ser notades per Coromines 1983. Però, tal com s'esmenta a Par (I923: I7I), la interacció entre el temps de l'oració i el valor semanticoaspectual del verb ja la va notar Diez (Grammaire des langues romanes), qui afirma que els verbs perfectius «no tenen passiva en lo present, imperfet y futur, temps en los quals lo llatí no’s construhía ab "esse”.»

9. Algunes seqüències són possibles com a passives estatives (també adjectives o lèxiques, segons les terminologies); ho indiquem amb el coixinet \#. 
Taula 2. Restriccions gramaticals i lexicoaspectuals de les construccions passives (extret de Mendikoetxea 1999)

\begin{tabular}{|c|c|c|c|}
\hline & Aspecte gramatical & \multicolumn{2}{|c|}{ Aspecte lèxic } \\
\hline :) Passiva & - Temps present amb Vs perfectius & $\begin{array}{l}\text { - Verbs imperfectius } \\
\text { - Activitats (atèlics) }\end{array}$ & Passiva adjectiva \\
\hline \multirow[t]{2}{*}{ (:) Passiva } & $\begin{array}{l}\text { - Present simultani o díctic } \\
\text { - Present històric } \\
\text { - Present habitual }\end{array}$ & \multicolumn{2}{|c|}{$\begin{array}{l}\text { - Transicions (realitzacions, assoliments } \\
\text { tèlics) }\end{array}$} \\
\hline & $\begin{array}{l}\text { Les restriccions sintàctiques d'aspecte } \\
\text { no són exclusives de les oracions passi- } \\
\text { ves: «Las construcciones pasivas no pre- } \\
\text { sentan restricciones de aspecto sintácti- } \\
\text { co que no afecten a las construcciones } \\
\text { activas equivalentes.» (1618) }\end{array}$ & \multicolumn{2}{|c|}{$\begin{array}{l}\text { «Sólo los verbos perfectivos que expresan } \\
\text { eventos o transiciones pueden aparecer } \\
\text { libremente en construcciones de pasiva } \\
\text { perifrástica en español.» (1623) }\end{array}$} \\
\hline
\end{tabular}

D'acord amb aquestes restriccions, (6) només és possible amb interpretació estativa com a passiva lèxica o adjectiva. ${ }^{10} \mathrm{~A}(7)$ caldria una interpretació díctica ad oculos ${ }^{11}$ o bé una interpretació de present històric per ser acceptable (A les 20:44 és assassinat l'ostatge). Pel que fa a la agramaticalitat o inacceptabilitat ${ }^{12} \mathrm{de}(8)$, Grimshaw $\&$ Vikner (1993) argumenten que els verbs que denoten realitzacions constructives necessiten un adjunt en passiva, ja sigui el SP complement agent o un adjunt temporal o locatiu:

(I2) La casa ha estat construïda*(\{en dues setmanes/en una zona protegida/per un milionari\})

(I3) La casa ha estat destruïda

Segons aquests autors, aquests verbs denoten esdeveniments complexos, consten d'un subesdeveniment activitat/procés i d'un subesdeveniment estat resultant. En la veu activa, l'agent i el tema legitimen cadascun un d'aquests esdeveniments. En la

Io. No entrem en la debatuda qüestió de l'auxiliar de les passives estatives en català contemporani. Vid. Ramos (2002-2008).

II. "[...] el testigo real (o ficticio) del acto da noticia de él en el mismo momento que se produce.» (Fernández Ramírez I95I: 424, citat a Mendikoetxea 1999: I618).

I2. Els verbs que denoten realitzacions constructives, tot i ser agentius i poder ser tèlics — segons que portin o no un tema incremental definit - només admeten la passiva en condicions molt restringides. 
veu passiva, la supressió de l'agent deixa un dels subesdeveniments sense ancorar i cal un adjunt per fer-ho. ${ }^{13}$

La anomalia de casos com (9) va ser notada per Coromines (1973): hi ha incompatibilitat entre el valor puntual del verb disparar i el valor duratiu de l'imperfet d'indicatiu. Si el subjecte fos un SD plural, es podria interpretar l'oració com una reiteració d'esdeveniments puntuals, cadascun dels quals distributivament relacionat amb una entitat de la pluralitat designada pel subjecte.

Pel que fa a (IO), Rizzi (I982) afirma que els complements dels verbs de mesura estan seleccionats, però no reben un paper temàtic referencial, no tenen un índex referencial. Aquest fet, en el model de gramàtica en què s'emmarca l'afirmació de Rizzi, implica que sigui impossible de traslladar el nominal, perquè la traça no podria establir una cadena de coreferència amb seu antecedent per mitjà d'un índex referencial. Tampoc no es poden passivitzar els predicats complexos o construccions predicatives amb verb lleuger, com les de (I4): ${ }^{14}$

(I4) Predicats complexos:

a. *La guitza ha estat feta sempre per la sogra

b. ${ }^{*} \mathrm{El}$ son va ser trencat pel despertador

c. ${ }^{*}$ La paciència va ser perduda per la mare

Els nominals de (I4) no són referencials (no són arguments), no tenen índex i no poden ser desplaçats.

Pel que fa a (II), sembla que només el coneixement del món — la impossibilitat que elsxiprers tingui un valor agentiu — pot determinar l'anomalia d'(II) contraposada a l'acceptabilitat de (I5) i (I6):

(I5) La casa va ser envoltada pels policies

(I6) La casa era envoltada de xiprers

I3. Complementàriament a aquesta explicació n'hi ha una altra basada en part en l'estructura argumental i en part en l'estructura informativa. Si suposem que en les oracions amb un predicats de creació constructiva el tema és pressuposat (semblant semànticament a un hipònim o objecte cognat), aleshores ens adonem que l'adjunt (ja sigui del complement tema o oracional —no podem entrar en aquesta qüestió) és necessari també en l'oració activa en molts casos: El promotor ha construït cases *(\{unifamiliars / en una zona protegida / massa cares per al meu pressupost\}).

I4. La impossibilitat de passivitzar els predicats complexos s'havia relacionat amb les construccions idiomàtiques: una de les primeres explicacions fou que estan emmagatzemades al lexicó com un sol element i per això els seus components no poden ser manipulats a la sintaxi. (Vegeu en aquest sentit Fraser 1970. Per a un enfocament centrat en l'estructura lèxica, vid. Mateu \& Espinal 2007 i Espinal \& Mateu 2010 i les referències que s'hi citen). 
Hi ha, però, una explicació gramatical del contrast. El subjecte d'un verb com envoltar, tal com assenyala Mendikoetxea (1999: 1624) per al seu corresponent castellà rodear, "tiene la función semántica de tema no afectado (el elemento del cual se predica un lugar), mientras que el objeto tiene un significado locativo. En la perífrasis con estar, el elemento locativo es el sujeto sintáctico y el otro argumento verbal se expresa por medio de un sintagma preposicional introducido por de o pon». En termes de Hale \& Keyser (2002), es tractaria de «closques verbalitzadores» d'una relació de coincidència central entre dos elements. ${ }^{15}$ Els exemples de (I4) i de (I5) tenen estructures sintàctiques diferents: mentre que (I5) és una construcció agentiva amb un SPAg, (I6) és una construcció estativa amb un SP complement del PP o SA. ${ }^{16}$

Les oracions (passives) serien, doncs, el resultat de la interacció de diverses propietats:

(I7) Propietats de les oracions passives (primera aproximació):

a. Els trets del temps verbal.

b. El valor puntual o duratiu de la construcció (assoliments vs. realitzacions). ${ }^{17}$

c. La telicitat del SV, relacionada amb l'estructura argumental del verb.

d. L'agentivitat de l'argument extern.

Coromines (1973) focalitza en la relació entre (I7a/b). Mendikoetxea (I999) considera la telicitat condició sine qua non de la passiva i Bartra (2008) defensa que els predicats que entren en construccions passives tenen una estructura complexa. Seguint Grimshaw \& Vickner (1993), que al seu torn s'inspiren en Pustejovsky (199I), els predicats passivitzables tindrien una estructura esdevenimental complexa, amb una part iniciadora del procés o activitat i una part que reflecteix l'estat resultant.

Gehrke \& Grillo (2009) també posen l'èmfasi en les propietats aspectuals dels predicats, concretament en la telicitat, i afirmen que només els verbs transitius

I5. L'estructura aspectual i argumental de les construccions amb predicats com envoltar, cobrir, tapar, etc. és, al nostre entendre, més complexa del que es desprendria de Mendikoetxea (1999). A banda de la relació de coincidència central, hi ha un component MANerA, probablement realitzat en una arrel, que és el que dóna lloc a verbs lèxics diferents. Vegeu també Acedo-Matellán \& Mateu 20I4. Aquests verbs tenen una versió (interpretació) estativa — la que hem descrit— i una d'agentiva, cas en el qual hi hauria un component de procés o de canvi d'estat.

I6. L'adjunció d'un SP introduït per la preposició amb mostra els dos valors:

(i) La casa va ser envoltada amb gespa

(ii) $\quad *$ La casa era envoltada amb gespa

I7. Vendler (1967). 
Anna Bartra-Kaufmann

Els components de la passiva. Una perspectiva diacrònica

associats amb una estructura esdevenimental de realització o assoliment admeten formar passives. ${ }^{18}$

L'agentivitat es deriva del fet que, en l'estructura argumental, l'inici del procés ha d'estar legitimat per un ORIGINADOR, CAUSA O AGENT. ${ }^{19}$

\section{LES DADES DEL CATALÀ ANTIC I LA TEORIA DEL CANVI SINTÀCTIC}

Les oracions passives de les llengües romàniques contemporànies, com el català i el castellà, semblen obeir a les restriccions de (I6). Una primera ullada a les bases de dades del català antic (CA), en canvi, indicaria que aquesta varietat tenia molta més llibertat per formar oracions passives:

(I8) No só empès ne temptat per desalt de res qu' en vós los meus hulls hagen vist; (March, Poesies, 22, 17).

(19) li sia apparallat ·I - siti reyal en alt, en guisa que per tots estants en lo dit palau sia vist (Ordinacions con los reys e reynas d'Aragó..., 265, 23).

(20) D'açò fon raonat en consell (Fets, XIII, \$2).

(2I) E si aquestes coses los dits vicaris [...] defugissen que fos procehit contra ells (Metge I432, citat per Par 1923: 175).

(22) E fonch feta crida que lo sendemà, [...] tothom hagués a fer festa (Safont, Dietari, $\mathrm{XV}, \mathrm{I} 2 \mathrm{O})$.

L'exemple (I8) conté el participi passat, empès, d'un verb atèlic, que segons alguns autors admet marginalment la passiva (vid. Masullo, 200I i les referències incloses); l'exemple (I9) conté el verb de percepció veure, considerat no agentiu (Ho vaig veure tot sense voler); a (2O) i (2I) hi ha passives impersonals, un tipus de passiva existent en llatí, però desapareguda en CC; (22) conté diversos elements que la fan impossible en CC: un predicat complex amb un verb lleuger fer i un subjecte escarit abstracte no referencial que forma part del predicat complex — de fet, n'és l'element predicatiu.

Pel que fa a la sintaxi diacrònica, assumim les hipòtesis de (23) i (24):

I8. «Only those transitive verbs that are associated with an accomplishment or achievement event structure (involving ВеСОмЕ) should be able to form passives» (Gherke \& Grillo 2009: 242).

19. Agrupem els tres termes perquè en molts casos no impliquen diferència de gramaticalitat: Tot el conflicte va ser originat \{pel primer ministre / per una mala administración dels diners\} (Gràcia 1987). 
(23) La hipòtesi Borer-Chomsky (Baker 2008):

Tots els paràmetres de variació es poden atribuir a diferències en els trets dels nuclis funcionals.

(24) Teoria de la inèrcia en el canvi sintàctic (Longobardi 200I: 277-78):

i. La sintaxi en si mateixa és diacrònicament completament inert. ${ }^{20}$

ii. Per «canvi sintàctic' s'entén el canvi en els trets formals dels ítems del lexicó.

iii. El canvi lingüístic pròpiament dit només es pot originar com un fenomen d'interfície.

Els principis de (23) i (24) són compatibles amb les propietats de la gramaticalització, el tipus de canvi lingüístic més sistemàtic, reinterpretat dins el model minimalista com la conversió d'una categoria lèxica en una categoria funcional. Roberts \& Roussou (2003) defineixen la gramaticalització com la creació de nous exponents [morfemes] de categories funcionals a partir de categories lèxiques. Gelderen proposa que els canvis es produeixen de forma cíclica i que obeeixen a principis d'economia. A (25) i (26) resumim les principals hipòtesis:

(25) Gramaticalització (Roberts \& Roussou 2003): ${ }^{21}$

La gramaticalització consisteix en la creació d'un morfema funcional a partir d'una categoria lèxica.

(26) Cicle del canvi lingüístic (van Gelderen 20II):

a. Un nucli té prioritat sobre un sintagma.

b. L'operació d'unió s'ha de retardar al màxim.

c. Són preferibles els elements amb menys trets semàntics i interpretables, d'acord amb la jerarquia:

\begin{tabular}{|c|c|c|c|c|}
\hline Adjunt & $>$ & especificador & $>$ & Nucli \\
\hline
\end{tabular}

20. En la teoria minimista, l'únic mecanisme del sistema computacional (la sintaxi) és la regla d'unió (Merge), de manera que la invariància sintàctica se segueix de forma natural: només hi pot haver variació que provingui de les diferències en les propietats formals dels elements units.

2I. [...] grammaticalization, the process by which new exponents of functional categories are created [...], involves structural reanalysis so that some new element comes to be merged in a functional position F. The structural reanalysis is always simplification in the precise sense defined by the simplicity metric in (23) [...]:

(23) A structural representation $\mathrm{R}$ for a substring of input text $\mathrm{S}$ is simpler tan an alternative representation R' if R contains fewer formal feature syncretisms tan R'. (Roberts \& Roussou 2003: 234). 
d. Cicle del canvi:

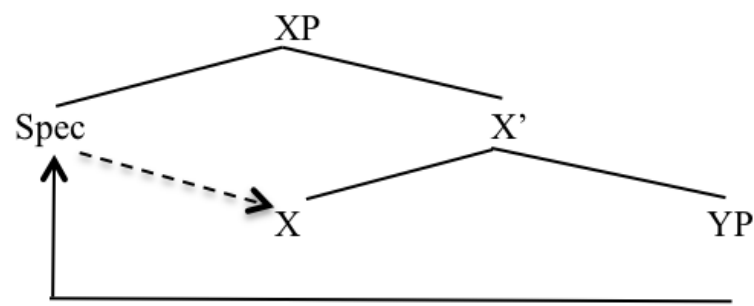

La fletxa contínua mostra el trasllat d'un sintagma a la posició d'especificador i la discontínua, el canvi diacrònic per mitjà del qual es crea el nucli funcional.

Les dades de (19) - (23) no s'ajusten a les restriccions que presenten les oracions passives en el CC, però són difícils d'explicar en el marc d'aquesta teoria del canvi, perquè els mateixos verbs que ara rebutgen la passiva l'admetien en CA. En les properes seccions mostrarem que els canvis són menors i en tot cas atribuïbles a propietats de les categories funcionals.

\section{ALGUNES ORACIONS PASSIVES INESPERADES EN CA. UNA PRIMERA APROXIMACIÓ}

A continuació presentarem algunes altres dades del CA que aparentment no respecten les restriccions comunament assumides.

\section{I AGENTIVITAT}

La necessitat que el predicat ${ }^{22}$ sigui agentiu o intencional és un requisit bàsic de les oracions passives (Mendikoetxea I999, $\$$ 26.3.I.2: I672). ${ }^{23}$ Un contraexemple aparent a aquesta exigència en CA són els verbs de percepció. Considerarem dos dels

22. Insistim en el fet que es tracta del predicat i no del verb tot sol, com es veu clarament en les combinacions $\mathrm{V}+\mathrm{SD}$ en els casos de verbs que poden ser lleugers o no:

(i) Les pedres van ser portades per esclaus nubis

(ii) $\quad$ ? /La malaltia va ser portada amb molta dignitat per en Job

(iii) $\quad * *$ Deu anys van ser portats esperant per en Job

(iv) Aquests quadres han estat donats a l'hospital per un mecenes

(v) ?? /*Un cop de mà ha estat donat per l'Ismael al Jeremies

23. «[...] la pasiva perifrástica se "especializa” en acciones de carácter puntual, con objetos "externos", y un marcado carácter intencional que denota la existencia de un sujeto implícito delimitado». 
verbs tradicionalment considerats estatius: veure i tenir i argumentarem que no són casos prototípics d'estativitat pura. Aquests verbs poden estar associats a categories funcionals que legitimen els components de les oracions passives.

\section{I.I El verb veure}

Els verbs de percepció s'han classificat en dos grups: verbs d'acció voluntària, com mirar i escoltar i verbs de percepció no intencionada, com veure i sentir. Només aquests darrers admeten l'elevació de clític: ${ }^{24}$

(27) a. $L$ 'he vista marxar

b. ${ }^{*} \boldsymbol{L}$ 'he mirada marxar

Les altres proves adduïdes són l'imperatiu pragmàticament reeixit (28), els adjunts de finalitat (30) i els adverbis de manera (30):

(28) a. Mira-la!

b. *Veu-la!

(29) a. Va mirar (bé) el paisatge per poder dibuixar-lo

b. ??/*Va veure el paisatge per poder dibuixar-lo

(30) a. Va mirar intencionadament el contingut de la maleta

b. *Va veure intencionadament el contingut de la maleta

No serien esperables passives com:

(3I) li sia apparallat $\cdot \mathrm{I} \cdot$ siti reyal en alt, en guisa que per tots estants en lo dit palau sia vist (Ordinacions [...] d'Aragó, 265, 23).

(32) Era per ella contínuament mirat e vist (Curial, 47, 24-25).

(33) si persona és [vi]st[a] a él semblant; (Usatges, 57, 1. I2).

Els exemples amb veure són molt abundants a la llengua antiga:

(34) Al qual afermament és vista fer fe assò que alscuns osses d'aquels imfants són tan grans, que no és semblant que fosse de $\cdot \mathrm{II}_{3}$ ayns. (Vides, 99.3).

(35) Ab tan bona fama e sens mala sospita, que no fo vista ni trobada... (Clams, I, I45.20).

(36) per lo patró e per altres de luny fonch vista la galera del cossari, (Curial, 275, I4)

24. Kayne (1975), Rizzi (1982), Hernanz \& Rigau (1984), Alsina (2002/2008), entre molts altres. 
(37) ý així es vista la antiguetat de la Parròquia ý el gran descuit de los archius de esta (Memòries d'un capellà del segle XVIII, 42.33).

Significativament, en contrast amb veure, es troben molt pocs exemples amb el verb oir:

(38) Veu és ö̈da en Rama de molt plant e plor (Les edats i l'epistola de Jesucrist, Fol. 234b, 1. 2).

(39) E aquesta veu fo ö̈da per tots quants aquí eren (SVF, Sermons, p. VI, I4O, 1. 27).

(40) una cosa per a salvar —ó tot, la més estranya que com vos hé dit jamay sia oïda (Col.loquis, 99.2).

Les restes etimològiques d'imperatius amb el verb veure, gramaticalitzades com a marcadors de modalitat (viam, mem), ${ }^{25}$ fan suposar un argument ORIGINADOR o AGENT. ${ }^{26}$

A més, hi ha en llatí videor deponent que té el sentit de semblar, tenir l'aparença (físicament o metaforica) de. Aquest sentit es conserva, en el català i el castellà, sobretot d'Amèrica: ${ }^{27}$

(4I) Es veu que està malalta

(42) Se ve que tendremos elecciones pronto.

(43) Te ves muy bien.

25. Vid. $D C V B$, s. v. veure. <http://dcvb.iecat.net/>.

26. Hi ha diverses en què el verb veure no és un verb estatiu pur. A banda de la passiva, admet construccions progressives (\#T'estic veient), la modalitat deòntica (Cal que vegis aquests documents, L'hauria de veure sa mare). En castellà, tant antic com contemporani, es troben exemples del verb veure en sentit agentiu, tant de percepció física (i, ii, v) com metafòrica (iii, iv):

(i) ved esta carta del dicho señor rey d'esta otra parte escrita (I464, Docs. Archivo Mun. de Guadalajara CORDE).

(ii) que vays a vuestra posada y mirad lo que allí hallaréys escrito, y ved aquí las laves de vuestra cámara (IsII Trad. de Tirante el Blanco, CORDE).

(iii) Pues ved si queréis decir algo a estas seńoras por la despedida (I550, Arce de Otárola, J. de CORDE).

(iv) Ahora vean ustedes la diferencia entre paleografía y neografía. (CREA).

(v) vean ustedes a Juanón en la posición del pivote. (CREA).

El contrast entre mirar i ver manifest a (ii) evidencia que la diferència no és l'agentivitat: mirar és duratiu (una activitat) i ver és un assoliment puntual ('passar a tenir la percepció visual de'), que, a més a més té un valor díctic, que es conserva en les lexicalitzacions díctiques del català vetaci, vetaqui (<http://dcvb.iecat. net/>) i les deòntiques jussives: Ves que no caiguis. (Vid. també García Hernández (1976), per a qui denotaria una 'actividad intencional de fijación visual').

27. DRAE, <http://dle.rae.es/?w=diccionario > 
Construccions com (44) demostren l'existència d'un estat resultant amb veure:

(44) a. El judici ha quedat vist per (a) sentència

b. Vista la situació, ens hem de vendre la casa

Una partició absoluta basada en un tret [+/- agentiu] no permet explicar les característiques de veure. ${ }^{28}$ Es pot suposar que — si més no en determinats usos- té un argument eventiu $<e>\mathrm{i}$ probablement un argument ORIGINADOR. ${ }^{29} \mathrm{Si}$ considerem les categories funcionals que legitimen l'argument extern i la noció de $\langle$ CAUSA $>$ (Chomsky 1995, Kratzer 1996, Alexiadou et alii 20I5), podem suposar que el verb veure projecta un node $S v$ (i segurament un node $S V e u$ ). La major presència de passives amb veure en CA que en CC seria una qüestió d'especialització en l'ús.

\section{I.2 El verb tenir}

El verb tenir es considera estatiu i, per tant no passivitzable. En CA es troben molt pocs exemples en els quals tingui el sentit actual, ni tan sols el sentit etimològic de mantenir, sostenir, aguantar:

(45) La Benaurada Verge no era tenguda sotz aquela lig de purificació per so cor: no enfantà, reebuda sement d' ome mas per mesclat espirament. (Vides, 244.6).

(46) enaxí com si aquella cosa que per ell era tenguda fos en veritat venuda, car permutació o escambi semblant és a venda. (Furs, r. 134, f. 17, 1. 4)

(47) e de la paret isqué una mà, tres dits tenint una ploma a scriure. (SVF, Sermons, vI, ISI, 37).

(48) e axí quasi en tot fou tenguda la pràticha segons la serimònia del dit don Karles. (Solemnitats de B., 2, p. 26I, 1. 22)

(49) segons sóts tengut com a senyor nostre (Epist. Val. Med., I).

A (46) i (47), sembla que el verb té l'ús modern, però, com diu Par (1923:I20) «significava 'tenir en la mà, servar, mantenir, ocupar, pararse, retenirse'», tant en

28. Per als diferents valors i usos del verb en llatí, vid. Oxford Latin Dictionary s. v. video.

29. Utilitzem el terme en el sentit de Ramchand (2008), que considera que els predicats es poden dividir en tres subesdeveniments que traduïm com SInici, SProcés i SResultat, cadascun dels quals introdueix un participant en el seu especificador; respectivament ORIGINADOR, AFECTAT, RESUlTANT (traducció nostra). Agraïm a un revisor anònim les observacions sobre el valor explicatiu d'aquesta via d'anàlisi. 
català com en castellà. En la major part de casos trobem tenir forma part d'un predicat complex (50) o de la construcció deòntica (5I): $:^{30}$

(50) Quant la cort fo tenguda, (Desclot, Crònica, II, I60, I4).

(5I) que no n'és tenguda de pagar ren, (Cost. Tortosa, 196. 17).

Defensem que en aquest valor etimològic té un argument ORIGINADOR i les projeccions funcionals que l'hostatgen. Es constata també en llatí:

(52) sin autem [ei] locum tenere uellent ("però si [ells] volgueren ocupar la posició...", Caes., Gall. 5, 35, 4).

(53) sed is locus ab his... tenebatur ("però la posició estava ocupada per ells...», Caes., Gall. $7,36,7)^{31}$.

El verb tenir, doncs, en CA mostra ambivalència respecte de l'estativitat. ${ }^{32} \mathrm{D}$ 'una banda, admet morfologia imperativa, encara que el significat no sigui sempre un acte de parla jussiu o directiu, sinó potser optatiu:

(54) lo quint que tingues a tots justícia fortment, (Dotzè, I, vol. I, p. 306, 1. 3I).

(55) tingues libertat de dar -los mort adolorida. (Tirant II3I, I5)

(56) La mia complanta, no la tingues sacreta; (Memorial pecador, p. 250, 1. 20).

D’altra banda, però, en l'ús tradicionalment anomenat "possessiu» selecciona nominals predicatius — de manera que forma predicats complexos- (50) o oracions reduïdes $(57-58)$ :

(57) E la dona, tenint la vista baxa (Decameró, 26I, I5)

(58) [...] tenint en la mà un sach foradat (Memorial pecador, 212, I).

30. No podem presentar aquí un estudi estadístic precís, però en el $C I C A$ en alguns segles no hi ha cap exemple de tengut/tenguda que no sigui de la construcció d'obligació o del passat perfet amb haver.

3I. Exemples de Baños Baños (2008, p. 17). La nostra traducció es basa en la seva castellana.

32. En (i) i (ii) el participi descriu el resultat d'un esdeveniment que comporta un cert dinamisme, com mostren els verbs sinònims entre parèntesis:

(i) els fills tinguts (= obtinguts) del primer matrimoni

(ii) les converses tingudes (= mantingudes) amb el director

(G. Rigau, c. p.) 
Per explicar els valors de tenir adoptem bàsicament el model de descomposició lèxica de Hale \& Keyser (1993, 2002) i les importants aportacions de Rigau (1997) i Fernández-Soriano \& Rigau (2009) pel que fa als verbs lleugers ésser, haver, tenir (cat.), llevar, tener (esp.). Seguint la tradició iniciada en Benveniste sobre les relacions semàntiques i sintàctiques entre ésser i haver i represa a Kayne (1993), aquestes autores proposen que el verb tenir d'oracions com (59) és un verb lleuger que selecciona un P de coincidència central (estativa), l'especificador de la qual seria el subjecte i el complement contindria un constituent complex amb valor proposicional (una predicació en la qual també hi ha una P de coincidència central o una oració completa):

(59) Tener temporal en variants de l'espanyol d'Amèrica

a. Tenía un año de estar fundado

b. Los pueblos indios ya tenemos mucho tiempo oyendo esto

c. Ya tengo tres años que no me hablo con ella

(6o) $\quad\left[\mathrm{V}\left[\mathrm{V}\left[_{\mathrm{SP}}\left[{ }_{\mathrm{SN}}\right.\right.\right.\right.$ los pueblos indios $]\left[_{\mathrm{P}}\left[\mathrm{P}_{\text {Coincidència Central }}\right]\left[{ }_{\mathrm{ORed} / \mathrm{SP}}\right.\right.$ mucho tiempo oyendo esto $\left.\left.\left.\left.]\right]\right]\right]\right]$

L'especificador de la $\mathrm{P}$ serà legitimat a través de la concordança amb $\mathrm{T}$ i el subjecte de l'oració podrà rebre Cas acusatiu gràcies a la incorporació de la $\mathrm{P}$ en el $\mathrm{V}$ (Rigau 1997). ${ }^{33}$ Suposem que en CA tenir té valor esdevenimental i conté un argument ORIGINADOR. Aquest valor etimològic es correspon amb una estructura més complexa que no pas l'actual descrit a Fernández-Soriano \& Rigau (2009). La relació dinàmica es codifica en una $\mathrm{P}$, també abstracta, de coincidència terminal, de transició o allativa, que selecciona la P de coincidència central:

$$
\text { [V [ V TeNIR } \left.\left[_{S \mathrm{P}}\left[\mathrm{P}_{\mathrm{P}}\left[\mathrm{P}_{\text {CTer }}\right]\left[_{\mathrm{SN}} \text { vos }\right]\left[_{\mathrm{P}}\left[\mathrm{P}_{\text {CCent }}\right]\left[\left[_{\text {ORed/SP }} \text { lo rei com a senyor }\right]\right]\right]\right]\right]\right]
$$

El fet que actualment el verb tendeixi a tenir solament una interpretació estativa pot ser resultat d'un procés de semantic bleaching de la P allativa incorporada en el $V$ lleuger. Aquest procés tindria com a correlat la pèrdua del tret no interpretable no validat de $\mathrm{S} v$ (o $\mathrm{SVeu}$ ), per la qual cosa no es pot legitimar un argument agentiu. Amb tot, també s'ha defensat que els predicats estatius no tenen tots el mateix nivell d'estativitat. Jaque (2013), partint de l'estratificació de l'estructura dels predicats en SInici, Sintagma Procés i Sintagma Resultat proposada a Ramchand (2008) ${ }^{34}$, considera que els predicats possessius projecten un SInici amb un argument extern, mentre que altres predicats estatius només codifiquen una relació de coincidència central.

33. No podem entrar aquí en la problemàtica específica de les oracions reduïdes.

34. Vg. nota (3I).

Caplletra 61 (Tardor, 2016), pp. 295-327 
En definitiva, les diferències en el valor [+/- dinàmic] del verb tenir es pot atribuir a canvis en els element morfosintàctics abstractes de l'estructura lèxica, replicats en l'arquitectura funcional projectada pel predicat. ${ }^{35}$

En aquesta secció ens hem referit a dos verbs aparentment considerats estatius, i hem conclòs $(a)$ que el valor d'estativitat és més aviat graduable que no pas nítidament positiu o negatiu $\mathrm{i}(b)$ que les diferències es poden relacionar amb propietats de les categories funcionals presents a l'estructura. A continuació ens referirem a la restricció de telicitat.

\subsection{LA PASSIVA I LA TELICITAT}

En la bibliografia s'ha argumentat que només els assoliments i les realitzacions admeten la construcció passiva. Els exemples següents inclouen activitats (honrar, servir), processos sense terme temporal (mirar, empènyer), estats amb argument EXPERIMENTADOR:

(62) per què fou aquí deliberat e conclòs en la forma següent, (Solemnitats Barcelona, I, 97, 19).

(63) D'açò fon raonat en consell (Fets, \$2).

(64) ço és saber, que Déus vol ésser honrat, servit, en ésser menbrat, entès, amat per hom. (Llull, Merav., IV, 25, 22).

(65) No só empès ne temptat per desalt de res qu' en vós los meus hulls hagen vist; (March, Poesies, 22, 17).

(66) Dient lo dit Muntanyans, que sobre les dites coses fesen la justícia, cor ell no deu esser mirat per lo dit terrat, $[\ldots]$ que ell no pusca esser mirat. $[\ldots]$ per tant que no sia mirat [...] ]en guisa e en manera que ell no pusca esser mirat. (Mostassaf, I, I5I, I5).

(67) era empesa tant ... (Solemnitats Barcelona, 2, 255.4).

(68) volent conèxer [...] si serien empesos d' enveja o per engraciar -se a tu. (Curial, 50, 37).

(69) per zo qe la caritat de Déu sia espandida e.ls nostres cors. (Homilies, II8, 30).

(70) per so com era molt amat per tots los moros per la sua molta virtut. (Tirant, II, CLIX).

35. Hem de deixar per un altre treball una anàlisi detallada d'aquest verb. Cal tenir en compte que el pas del verb tenir a verb de possessió té a veure amb la gramaticalització i generalització d'haver com a auxiliar de perfectivitat (vid. Pérez Saldanya 1998, 2013; Ramos 2000, 200I; entre d'altres). 
Per a Gehrke \& Grillo (2002), la passivització requereix un SV amb dos subesdeveniments: procés i resultat. ${ }^{36}$ Per explicar (62) - (70) podem prendre dues direccions alternatives: o bé podem suposar — contra Gehrke \& Grillo- que la telicitat no és una condició necessària per a la passiva, o bé podem argumentar que aquestes frases contenen un predicat tèlic.

La telicitat del predicat téa veure amb la presència d'un tema incremental definit (Tenny (1994). Els exemples següents mostren el paper discriminador dels adjunts:

(7I) ??El calaix va ser mirat en cinc minuts

(72) *Mirat el calaix, l'Eva ja no va saber on buscar

(73) (Un cop) (va haver) mirat dins el calaix, l'Eva ja no va saber on buscar

(74) ?Aquella taula va ser empesa pel Martí

(75) (Un cop) empesa aquella taula, al Martí tots els mobles li semblaven lleugers

(76) La taula va ser empesa fins al menjador en cinc minuts

Proposem que el valor semàntic [+/- tèlic] del predicat és una funció composicional de tots els constituents de l'oració. Cal distingir els arguments, concretament el tema incremental, dels adjunts. El primer ha de ser legitimat per concordança en una projecció funcional i els elements no seleccionats donaran lectures acceptables o inacceptables a la interfície. En resum, defensem, en la línia de Borer (2005), que la telicitat es deriva de l'estructura; no és una propietat intrínseca dels predicats.

Es pot defensar que la categoria rellevant és SAsp i que la presència d'un argument en una projecció aspectual SAsp perfectiva comporta la interpretació d'estat resultant. ${ }^{37,38}$ La telicitat no seria, doncs, una conditio sine qua non de la passiva. ${ }^{39,} 40$

36. Aquesta idea es remunta a Pustejovsky (I991) i ha estat represa amb variacions en diversos treballs.

37. Guéron (2006) també defensa, dins un marc relativament diferent, que cal separar telicitat (derivada de les propietats del $\mathrm{S} v$ ) de perfectivitat (propietat de SAsp, superior en l'estructura).

38. L'adjunt un cop augmenta l'acceptabilitat de la frase, segurament perquè es legitimen en una projecció temporal alta. D'altra banda, a (76), l'adjunt que legitima la interpretació tèlica no és pas fins al menjador, sinó en cinc minuts, com mostren (i) i (ii):

(i) ??/*Vaig caminar fins a l'estació en mitja hora

(ii) ??/*Vaig empènyer el cotxe fins al garatge en deu minuts

(J. Mateu c. p.).

39. Aquesta idea la defensa també Napoli (2013) en relació amb les passives impersonals del llatí i un revisor anònim, qui, a més suggereix de relacionar-la amb la controvèrsia sobre la relació entre telicitat i inacusativitat. Deixem per a un altre treball continuar explorant aquesta interessant via d'anàlisi.

40. Un revisor anònim suggereix que les estructures (62) - (70) tal vegada no són reflex de la parla espontània, sinó de rutines heretades del llatí. Aquesta observació concorda perfectament amb la tesi defensada 


\subsection{LES PASSIVES AMB PREDICATS COMPLEXOS}

En CA és possible passivitzar predicats complexos formats amb un verb lleuger i un nominal escarit no referencial i no argumental predicatiu: ${ }^{41}$

(77) fo moguda qüestió entre ells. (Sermons, XCII).

(78) e que sia fet protest ab scriptura (Crims, Xv, carta 2, a.).

(79) no sia fet quitament de lurs censals. (Algezira)

(80) E fonch feta crida que [...], tothom hagués a fer festa. (Safont, Dietari: I20, s. Xv)

(8I) Et per ço com era estat fet manament [...] que [...] se callassen (Ep. Pere III $(2 / 2)$, carta I4).

(82) E fo establiment fet que [...] (Llull, Blanq., II, LVIII).

(83) en aquel temps que lo malefici fos feit ... (Clams, I, p. I27).

(84) manament és estat feit a vós de part d'En B. Çaffont. (EVM, I, 7).

(85) denunciació fo feita en poder d'en P. De la Franega. (Clams, I, p. I27)

En la major part de casos, la posició del nominal concordant és postverbal, darrere el PP. Assumim que aquesta és la posició canònica i que els casos de nominal preverbal s'han d'interpretar com a casos de Fronting (Batllori \& Hernanz 2015). El nominal no es legitima en la projecció de $T$, sinó en la projecció ampliada d'una categoria de rang més baix, SAsp, i no concorda amb cap projecció alta, és a dir, T. El PP té trets no validats de gènere i nombre ([uGen] i [uNom], per la qual cosa estableix una relació de concordança amb un $\mathrm{SN}$ amb aquests trets validats. El trasllat a la posició perifèrica en els casos de Focus Fronting no té els mateixos requisits de constituència $^{42}$ i, per tant, el desplaçament és permès. En definitiva, les construccions «passives» amb predicats complexos no són sinó construccions perfectives amb un PP a SAsp i un SN escarit que legitima els trets nominals del participi.

en aquest treball des d'una perspectiva sintàctica: el CA conserva les propietats de les categories funcionals de perfectivitat de les passives perfectives del llatí. D'altra banda, però, el fet que es trobin exemples d'aquest tipus en textos de gèneres diferents fa pensar que no es tracta d'una tradició discursiva específica (Kabatek 2008; 2009), sinó d'un fenomen general.

4I. Per una anàlisi en la línia de Hale \& Keyser (2002), vegeu Bartra-Kaufmann (20II).

42. Considerem exemples clàssics com LLUMS, comprarem, no quadres! 


\subsection{PASSIVES IMPERSONALS ${ }^{43}$}

Les passives impersonals existien en llatí, tot i que no eren gaire abundants i també n'hi ha en alemany contemporani, en neerlandès o en turc, entre altres llengües ${ }^{44,45}$ :

(86) Passives impersonals en llatí

a. disputatur in consilio a Petreio atque Afranio «es disputa en una reunió per Petrei y Afrani» (Caes., Civ., I.67.I)

b. invidetur enim commodis hominum ipsorum «es veu amb mals ulls un benefici personal» (Cic., De orat., 2.207)

c. pugnatum est ab utrisque acriter «es lluità per ambdós bàndols amb valor» (Caes., Gall., 4.26.I)

d. ex omnibus locis urbis in forum curritur. Quo simul ventum est [...] «des d'arreu de la ciutat s'acut corrents al fòrum. Quan van arribar [...]» (Liv., I.59.7)

e. sic itur ad astra «així s’arriba a les estrelles» (Verg., Aen., 9.64I).

f. Fit [...] invitatio ut Graeco more biberetur «Es feu invitació que es bevés a la manera grega» (Cic., Ver, I.66)

g. eatur "que (hi) vagin»( Sen., Thy, 330).

(87) Hier wurde den ganzen Aquí ser.Past.3Sg. el tot "Aquí es ballà tota la nit»

(88) Er wordt door de kinderen op het ijs geschaatst (neerlandès) Pron ser.PAST.3.Sg per els nens sobre el glaç patinar.PP «Fou patinat pels nens»

(89) Burada çalıshılır Abend getanzt (alemany) «Aquí fou treballat»

43. El terme inclou construccions diferents segons la perspectiva teòrica (vid. Napoli 2013 i Perlmutter 1978, probablement el primer a assenyalar la relació entre les passives impersonals i la distinció entre inacusativitat $\mathrm{i}$ inergativitat).

44. Pinkster (1992: I66) esmenta exemples de passives impersonals amb agent de Priscià: Curritur a me "curro». Aquest autor també destaca que se'n troben molt pocs exemples i els atribueix diversos valors, bàsicament el fet que l'agent sigui inespecífic o genèric i l'intent de focalitzar l'esdeveniment. Aquesta darrera observació és molt interessant. Es podria suposar que es trasllada a SFocus a la periferia esquerra i que té persona 3 per defecte. Deixem per a futures recerques un estudi a fons.

45. Els exemples (a) - (e) són de Baños Baños 2013. Agraeixo a Jaume Mateu la referència. (f) i (g) són de Pinkster (1992). 
En CA trobem molts casos d'impersonalitat semàntica, perquè l'absència de SPAgent porta a interpretar un agent arbitrari, però també alguns d'impersonalitat formal, en què un predicat inergatiu entra en una estructura passiva. Al primer grup pertanyen (90) - (93), mentre que (94) - (96) serien casos de verbs aparentment intransitius.

(90) que a mi sia honrat per donar e a vós de pendre. (Desclot, p. II., 6I, 1. 6).

(9I) $\mathrm{E} \mathrm{d}[\mathrm{e}]$ ço $\mathrm{d}[\mathrm{e}] \mathrm{l}$ bispat $\mathrm{m}[\mathrm{e}]$ tet pei[nn] ora ça e là é q[ue] vós ne siatz honrat. (Urgell, 2, p. 40I, 1. 36).

(92) fón manat a nosaltres que $[\ldots](E V M$, I03, 4.)

(93) Fo demanat on avia estat (Clams, I, p. I46.)

(94) Item, fou deliberat que [...] los verguers [...] fossen vestits de sengles gramalles (Barcelona, I, 66,4).

(95) D'açò fon raonat en consell $(E V M$, I24, I2)

(96) que fos procehit contra ells (Metge I432, apud Par 1923: 175)

En general, les llengües que tenen passives impersonals marquen les construccions passives amb morfemes específics; p. ex., el llatí amb la flexió en - $r$ en les formes de l'infectum, el neerlandès i l'alemany amb el verb de canvi d'estat worden/werden. ${ }^{46}$ Una categoria funcional amb trets no interpretables té dues vies per validar-los: trobant un element amb els trets corresponent validats i establint-hi una relació de concordança o bé directament fusionant-hi una morfologia que manifesti aquests trets. El segon és el mecanisme de les llengües de subjecte nul i T (Rizzi 1982, entre molts). De forma paral.lela, la passiva impersonal és possible en llengües amb morfologia passiva explícita, cas en què SVeu se satisfa amb la morfologia passiva, sense un argument intern. En CA la morfologia del PP faria aquest paper. Cal, però, un estudi més aprofundit dels possibles (pocs) casos de passiva impersonal en CA.

\subsection{EL TEMPS I LA FRONTERA AMB LES PASSIVES ESTATIVES}

Les passives perifràstiques dinàmiques no admeten bé els temps imperfectius. En aquests temps, les interpretacions possibles són: narració immediata ad oculos, valor reiteratiu o passiva adjectiva o estàtica que denota un estat resultant, sobretot en els casos de predicats no duratius:

46. El verb werden alemany és un verb que també indica canvi d'estat: Ich werde alt («Em faig vell/a»). 
(97) El policia \{\#és atacat /va ser atacat\} per un manifestant (mentre retransmetem)

(98) Els policies sempre són atacats pels manifestants

(99) Els dissidents \{\#són insultats /van ser insultats\} (pels seus antics companys de partit)

(IOo) La porta \{\#és tancada/va ser tancada\}

(IOI) Els traïdors són menyspreats

(IO2) La porta va ser tancada de cop

En CA, en canvi, oracions paral-leles a les presentades són abundantíssimes:

(IO3) aquell acte és més perillós qui és mirat per los anemichs (Arbre, p. I2O, II).

(I04) E ara lo tema és declarat (SVF, Ser: I2I)

(IO5) per so que sia manifestat a les gents que tu às conformat lo sant sagrament del babtisme. (Doctrina, I, 7I.5).

(Io6) e que aquell Ferrer ere nafrat e tot esper[d]ut (Clams, I: I38, 22).

(I07) Io som traït! (Muntaner, Crònica, 95, 7)

(Io8) e ques son aiustats quants sarrains ha de Catzalla (Fets, 799)

(Io9) si les coses daquest mon que son demanades de molts a molts (Fets, 337)

Aquest fet no és sinó herència del llatí. En primer lloc, en CA les passives adjectives o estatives es construeixen amb l'auxiliar ésser, de manera que cal el context per poder interpretar el valor estatiu o l'esdevenimental. En segon lloc, en llatí vulgar i CA el «verb en present amb interpretació passada ${ }^{47}$ no significa sinó valor de present perfet, el qual es dóna pel PP, d'acord amb el valor de les formes del sistema perfectiu de la passiva del llatí clàssic.

\section{CAP A UNA EXPLICACIÓ DE LES DADES}

En les seccions precedents hem mostrat que les diferències entre el CA i el CC són menors que no aparenten i hem apuntat cap a dues línies d'explicació. D'una banda, el valor semàntic i les propietats morfosintàctiques de les oracions passives no són atribuibles de forma exclusiva al predicat, raó per la qual defensem que una

47. «Com que aquests temps (...), jatsia portin "ésser" ab sentit present, signifiquen acció passada, llurs participis perden ab facilesa la noció verbal d'activitat, per a adquirir l'estable del adjectiu: per veure si jo dormia o stava descubert (3556), scarniran [...] les dones honestes si no seran tan orades com ells volrien (3639).» (Par 1923: 173). Vid. també Ramos (2000).

Caplletra 61 (Tardor, 2016), pp. 295-327 
aproximació de caire neoconstruccionista resulta la més adequada. Els predicats formen estructures sintacticosemàntiques complexes en les quals cada projecció té un determinat valor i legitima un argument. Seguim les importants aportacions de Borer 2005, Hale \& Keyser 1993 i 2002, Mateu 2002, Mateu \& Rigau 2002, Acedo-Matellán \& Mateu 20I4, Massanell \& Mateu 20I4, entre d'altres. De l'altra, es constata en CA la pervivència dels valors de les categories funcionals del llatí. Això ens permet de veure de forma més clara que en CC la naturalesa composicional de les passives. ${ }^{48}$

En aquesta secció volem relacionar ambdós aspectes per avançar en la comprensió del fenomen de la passivització.

A Bartra (2008: 2I20) s'hi diu que «Les oracions passives perifràstiques tenen valor esdevenimental» i s'identifica de manera simplificadora esdevenimental amb agentiu. A més, s'hi diu que «L'element que en les construccions passives comporta el valor passiu és el participi passat o passiu» i s'addueixen les construccions absolutes com a prova. Aquesta visió està basada en tractaments dels predicats esdevenimentals com el de Pustejovsky (199I), que considera que els predicats que denoten transicions contenen dos subesdeveniments, de manera que el primer consisteix en la no-existència del segon, com es representa a (III):

(IIO)

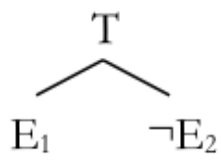

El participi passiu codifica la segona part de l'esdeveniment, però l'oració passiva requereix que el predicat sigui del tipus $\mathrm{T}$, és a dir, que es pugui interpretar un desencadenant en un estat inicial.

Hale \& Keyser (1993; 2002), en la seva representació sintàctica de l'estructura argumental, consideren que les estructures que denoten un canvi d'estat contenen un verb abstracte que codifica CAUSA, el qual selecciona una relació de coincidència terminal, <ct>, (considerada inicialment un predicat incrustat i posteriorment una P) que té en la posició d'especificador un nominal (Figura) i en la posició de complement una arrel que codifica l'estat resultant (Fons). Podíem dir que en una estructura com (II2), el SP denota l'estat resultant i el V que el selecciona codifica l'esdeveniment de transició. Recordem que Hale \& Keyser consideren que el subjecte no forma part

48. Un dels primers treballs a plantejar la qüestió en el nostre àmbit és Brucart (1990). 
de l'estructura lèxica del predicat i s'insereix en la sintaxi en l'especificador de la categoria funcional que tanca la projecció ampliada del SV, és a dir, T.

(III)

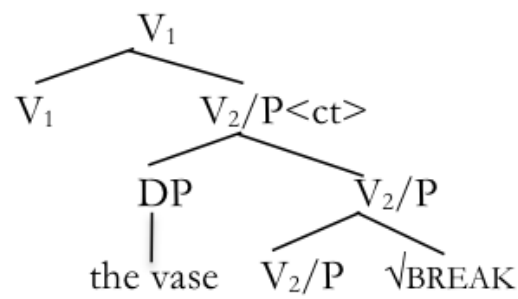

$\mathrm{V}_{\mathrm{I}}$ s'identifica amb el desencadenant de la causa. Chomsky (I995 \& seq.) reinterpretarà aquest $\mathrm{V}_{\mathrm{I}}$ com una categoria funcional $v$ responsable de la introducció de l'argument extern i que només té un estatus complet $\left(v^{*}\right)$ amb els verbs inergatius i transitius, mentre que els inacusatius i les construccions passives tenen un $v$ defectiu.

Al costat d'aquesta aproximació, segons la qual el node $v$ és defectiu quan no es projecta un argument extern - cosa que suposa codificar en aquest node la correlació de Burzio - s'ha proposat que el node $v$ és un node verbalitzador d'una arrel acategorial (en la línia del que proposa la morfologia distribuïda ${ }^{49}$ i que el node en el qual s’insereix l'argument extern és SVeu. ${ }^{50}$ (Kratzer 1996; Folli \& Harley 2007; Harley 20I3).

La visió que volem defensar de les estructures passives del català antic parteix de les assumpcions recents de la teoria de fases de Chomsky (200I). A partir de les dades observades, reformulem les generalitzacions descriptives a (II2).

(II2) Generalitzacions descriptives sobre les passives en CA

a. El valor perfectiu del PP i la concordança amb l'argument intern legitimen la construcció amb predicats aparentment atèlics i estatius.

b. L'existència d'un argument ORIGINADOR ${ }^{51}$ no és equivalent al concepte clàssic d'agentivitat.

c. Algunes passives impersonals semblen possibles.

49. Halle \& Maranz (1993), Maranz (1997), Harley \& Noyer (1999), Embick (2004), Embick \& Noyer (2007). 50. A Kratzer (1996) SVeu introdueix l'argument extern i assigna Cas Acusatiu; equivaldria a S $v$ (Chomsky 1995 \& seq.). Les necessitats d'adequació descriptiva forcen Harley (2013), entre altres, a proposar la necessitat de tenir alhora Sv i SVeu i altres autors han proposat STransitivitat (Jelinek 1998) o SPassiva (Alexiadou, Anagnostopoulou \& Schäfer 2015).

5I. Possiblement identificable amb l'Esp de SInici de Ramchand (2008). 
d. En oracions passives amb predicats complexos l'argument intern ha de ser legitimat en una posició baixa en l'ordre no marcat.

e. La possibilitat de l'auxiliar ser en temps imperfectius mostra la independència respecte de l'Aspecte, tant Intern o lèxic (SAspI, sota Sv) com Extern (SAspE, sobre Sv).

A continuació presentarem les principals assumpcions teòriques i la nostra anàlisi, que s'hi fonamentarà.

D’acord amb Chomsky (2015: 9), una llengua amb concordança «rica» com el llatí «lacks EPP [...] thus [...] keeping the parametric difference in terms of richness of agreement.» Per tant, $\mathrm{T}$ pot satisfer el seu tret $[+\mathrm{D}]$ amb la morfologia inflectiva de persona del V. Un altre element que mostra «riquesa» pel que fa als trets phi (gènere i nombre) és el $\mathrm{PP}$, perquè té gènere i nombre. Pel que fa a $\mathrm{S} v$, en les oracions passives - com en les inacusatives - és defectiu, ja que no acull l'argument extern. Per això el SD objecte no queda legitimat en la fase $v$ i pot validar el tret $[+\mathrm{D}]$ de $\mathrm{T}$ en una operació de readjunció (remerge) a T, en la fase C.

Suposem que en el cas que el verb sigui un participi, una projecció SAspecte $\mathrm{I}($ ntern), inferior a $S v$, acull l'argument intern, el qual satura la variable quantificacional del nucli, en el sentit de Borer (2005). ${ }^{52} \mathrm{Si}$ el verb té un argument ORIGINADOR, $\mathrm{S} v$ allotja el valor <CAUSA/ESDEVENIMENT>, però és defectiu pel que fa al Cas.

$$
\text { (II3) }\left[_{S v}\left[v<\text { CAUSA/ESDEVENIMENT }>\left[_{\mathrm{ASPI}}\left[\mathrm{SD} / \mathrm{SN}\left[_{\mathrm{SV}}\left[\mathrm{V}_{\mathrm{PP}} \mathrm{SP}\right]\right]\right]\right]\right]\right]
$$

El SD/SN intern satisfa la variable quantificacional de SAspI (és a dir, que «tanca» el SV lèxic pel que fa als arguments). Concorda amb gènere i nombre amb el $V_{\mathrm{PP}}$ dins d'AspI. En el cas que sigui un SN, com en les passives dels predicats complexos, ja no té cap altre tret: no és un argument i no té Cas. Per tant, no té cap tret que pugui concordar amb cap categoria més alta.

El participi té un tret validat de Perfectivitat i un tret validat de $v$ de manera que valida els trets verbals de $v$, i el tret de perfectivitat d'una categoria SAsp alta, que anomenem SAspE(xtern). Com que no té trets de T ni de persona, un cop aquí ja no hi ha cap altre tret que el requereixi.

$$
\text { (II4) }\left[_{\text {SAspE }} \mathrm{V}_{\mathrm{PP}}\left[{ }_{\mathrm{S} v}\left[v<\mathrm{CAUSA}>\left[_{\mathrm{AspI}}\left[\mathrm{SD}\left[_{\mathrm{SV}}\left[\forall_{\mathrm{PP}} \mathrm{SP}\right]\right]\right]\right]\right]\right]\right.
$$


Així, el $\mathrm{V}_{\mathrm{PP}}$ es trasllada a $v$ per validar els seus trets verbals i posteriorment a una categoria SAspecte E(xtern) per validar els trets de perfectivitat d'aquesta.

En cas que el nominal sigui un argument intern $S D$ podrà validar els trets de $\mathrm{D}$ de $\mathrm{T}$, ja sigui en la posició d'ESP de ST, ja sigui en una posició inferior per "concordança a distància» ja que, com hem dit, en les llengües de subjecte nul ST no té un tret que requereixi els trasllat d'una categoria al seu especificador. Un cop el V és a AspE, el $S v$ ja no té cap tret per validar.

Queda per explicar la presència de l'auxiliar ésser. El node $T$ té un tret no validat de temps [uT] que s'ha de validar mitjançant la inserció del verb ésser. ${ }^{53} \mathrm{La}$ independència del $V_{P P}$ respecte de l'auxiliar ser a $T$ explica el fet que la interpretació perfectiva «mana» sobre la temporalitat de l'auxiliar, cosa que no afecta la gramaticalitat de les passives en present i imperfet. Els subjectes preverbals haurien sofert un trasllat a alguna categoria funcional de l'àmbit de SComp (SFocus o STòpic).

$$
\begin{aligned}
& \text { (II5) }\left[_ { \text { STemps } } [ { } _ { \mathrm { T } } \operatorname { s e r } [ \mathrm { uT } ] ] \left[_{\mathrm{SAspE}} \mathrm{V}_{\mathrm{PP}}\left[_{S v}\left[v<\mathrm{CAUSA}>\left[_{\mathrm{AspI}}\left[\mathrm{SD}\left[_{\mathrm{SV}}\left[\forall_{\mathrm{PP}} \mathrm{SP}\right]\right]\right]\right]\right]\right]\right.\right. \\
& \text { (II6) }\left[_ { \text { SFocus } } \mathrm { SD } \left[_{\text {STemps }}\left[{ }_{\mathrm{T}} \operatorname{ser}[\mathrm{uT}]\right]\left[_{\mathrm{SAspE}} \mathrm{V}_{\mathrm{PP}}\left[_{\mathrm{S} v}\left[v<\mathrm{CAUSA}>\left[_{\mathrm{AspI}}\left[\mathrm{SD}\left[_{\mathrm{SV}}\left[\forall_{\mathrm{PP}} \mathrm{S} \bigoplus\right]\right]\right]\right]\right]\right]\right]\right.\right.
\end{aligned}
$$

Les passives impersonals del llatí s'expliquen per la presència a $S v$ de la morfologia passiva $-r$ (recordem que es dóna bàsicament amb verbs inergatius) que actua de morfologia «rica» i valida els trets d'aquesta categoria, a la manera d'object drop. ${ }^{54}$

\section{CONCLUSIONS}

En aquest treball hem mostrat que l'explicació de les oracions passives s'ha de fer tenint en compte alhora les propietats de l'estructura lexicoargumental i de l'arquitectura funcional de l'oració. Per fer-ho hem partit d'una aproximació al complex mosaic d'aquestes estructures en català antic i hem argumentat que no hi ha estructures excepcionals, sinó una complexa interacció de factors que dóna com a resultat la parametrització de les propietats segons els trets de les categories funcionals projectades pels elements lèxics. Més específicament, hem mostrat que algunes suposades

53. En el sistema de perfectum el funcionament seria més complex, probablement semblant al del CA. També es podria suposar que el node AspE [+perf] és seleccionat per un node Aux. Deixem aquestes qüestions per a recerques futures.

54. També podria ser SVeu el node responsable d'hostatjar la morfologia de passiva o bé que SAspE i SVeu no fossin sinó dues categories que s'activaria de forma complementària. Deixem per a més endavant aquesta qüestió. (Vg. Alexiadou, Anagnostopoulou \& Schäfer 20I5).

Caplletra 61 (Tardor, 2016), pp. 295-327 
diferències entre el CA i el CC són diferències pel que fa a l'ús i no a les propietats lèxiques dels verbs. Allà on els dos estadis es diferencien és a causa de les propietats de les categories funcionals, que permeten la legitimació del SN/SD argument intern en una posició baixa de l'estructura, una estructura que no es diferencia de la de les construccions participials més que per la inserció de l'auxiliar ésser per validar els trets de temporalitat de l'oració.

Anna Bartra-Kaufmann

Universitat Autònoma de Barcelona anna.bartra@uab.cat

\section{REFERÈNCIES BIBLIOGRÀFIQUES}

Fonts de les dades

CICA: Corpus Informatitzat del Català Antic. Dirigit per Joan Torruella (ICREA-UAB), amb la col-laboració de Manuel Pérez Saldanya (UV-IEC) i Josep Martines (UA-IEC), <http://cica.cat/>.

CORDE <http://corpus.rae.es/cordenet.html>.

$C R E A<\mathrm{http}: / / \mathrm{www}$. rae.es/recursos/banco-de-datos/crea $>$.

Diccionari català-valencià-balear $<$ http://dcvb.iecat.net/>.

Oxford Latin Dictionary. Ed. per P. G. W. Glare. Oxford at the Clarendon Press. Fascicle viII Sopor-Zythum.

Bibliografia

Acedo-Matellán, V. \& J. Mateu (20I4) «From syntax to roots: A syntactic approach to root interpretation», dins Artemis Alexiadou, Hagit Borer \& Florian Schäfer (eds.), The Syntax of Roots and the Roots of Syntax, Oxford, Oxford University Press.

Alexiadou, A. (20I4) "Active, middle, and passive: the morphosyntax of Voice», Catalan Journal of Linguistics, I3, pp. 19-40.

Alexiadou, A., E. Anagnostopoulou \& F. Schäfer (2015) External arguments in transitivity alternations: A layering approach, Oxford / Nova York, Oxford University Press.

Alsina, A. (2008 [2002]) «L'infinitiu», dins J. Solà (dir.) et alii, Gramàtica del català contemporani, vol. III, cap. 20, pp. 2389-2454. 
Baker, M. (1985) «The Mirror Principle and Morphosyntactic Explanation», Linguistic Inquiry, I6.3, pp. 373-4I5.

BAKeR, M. C. (1988) Incorporation: A theory of grammatical function changing, Chicago, Chicago University Press.

Baker, M., K. Johnson \& I. Roberts (1989) «Passive arguments raised», Linguistic Inquiry, 20, pp. 219-25I.

Baños Baños, J. M. (2008) «Las categorías verbales de persona, número y voz en latín», Madrid, Liceus. [E-eXcellence: <http://www.liceus.com/cgibin/aco/ areas.asp?id_area $=4>$.]

— (2013) «Dos tipos de intransitividad en latín: sintaxis y semántica», Ianua Classicorum. Temas y formas del Mundo Clásico, I, pp. 759-790.

Bartra Kaufmann, A. (2008 [2002]), "Les passives i les construccions que s'hi relacionen», dins J. Solà (dir.) et alii, Gramàtica del català contemporani, vol. II, cap. I6, pp. 2III-2I79.

- (2OII) «From mismatch to transparent argument structure: Some remarks on Old Romance Complex Predicates», dins N. Pomino \& E. Stark (eds.), Fachbereich Sprachwissenschaft der Universität Konstanz. Arbeitspapier Nr. I25. Proceedings of the V Nereus International Workshop: "Mismatches in Romance», Konstanz, Universität Konstanz, pp. I27-I49.

- (2015) «Approaching lexical restrictions in Old Romance Passives». [Exemplari de la presentació feta a l'Ibero-Romance Linguistics Fest, Queens College, University of Cambridge, 23-24/04/2015.]

Batllori, M. \& M. L. Hernanz (20I5) «Weak focus and polarity: Asymmetries between Spanish and Catalan", dins T. Biberauer \& G. Walkden (eds.), Syntax over Time: Lexical, Morphological and Information-Structural Interactions, Oxford, OUP.

Benveniste, É. (1960) «Être et avoir dans leurs fonctions linguistiques», Bulletin de la Société de Linguistique, LV, pp. II3-I34. [Repr. en Problèmes de linguistique générale, París, Gallimard, 1966, pp. 187-207.]

Borer, H. (2005), Structuring Sense II. The Normal course of events, Oxford / Nova York, Oxford University Press.

BRUCART, J. M. (I990) "Pasividad y atribución en español: Un análisis generativo», dins V. Demonte \& B. Garza Cuarón (eds.), Estudios de Lingüística de España y México, pp. I79-208.

Burzio, L. (1986) Italian syntax: A government-binding approach, Dordrecht, Springer. Chomsкy, N. (I99I) Lectures on Government and Binding, Dordrecht, Foris.

— (1995) The Minimalist Program, Cambridge, MIT Press. 
Chomsky, N. (200I [1999]) «Derivation by phase», dins M. Kenstowicz (ed.), Ken Hale: A life in language, pp. I-52.

- (2015) «Problems of projection. Extensions», dins E. di Domenico, C. Hamann \& S. Matteini (eds.), Structures, strategies and beyond. Studies in honour of Adriana Belletti, Amsterdam, John Benjamins, pp. I-I6.

Collins , C. (2005) «A smuggling approach to the passive in English», Syntax, 8.2, pp. 8I-I2O.

Coromines, J. (197I) «La passiva pronominal és generalment correcta i sovint no ho és la passiva amb ésser», dins Lleures i converses d’un filoleg, Barcelona, Club Editor, pp. 77-82.

Емвіск, D. (2000) «Features, syntax, and categories in the Latin perfect», Linguistic Inquiry, 3I(2), pp. I85-230.

- (2004) «On the structure of resultative participles in English», Linguistic Inquiry, 35.3, pp. 355-392.

Eмbick, D. \& R. Noyer (2007) «Distributed morphology and the syntax/morphology interface», dins G. Ramchand \& C. Reiss (eds.), The Oxford handbook of linguistic interfaces, Oxford University Press, pp. 289-324.

Espinal, M. T. \& J. Mateu (20IO) "On classes of idioms and their interpretation», Journal of Pragmatics, 42(5), pp. I397-I4II.

FernándeZ-Soriano, O. \& G. Rigau (2009) «On Certain Light Verbs in Spanish: The Case of Temporal tener and llevar», Syntax, I2, pp. 135-157.

Folli, R. \& H. Harley (2007) «Causation, Obligation, and Argument Structure: On the Nature of Little v», Linguistic Inquiry, 38, pp. 197-238.

Fraser, B. (1970) «Idioms within a transformational grammar», Foundations of Language, 6, pp. 22-42.

Freidin, R. (1975) "The analysis of passives», Language, 5I, pp. 384-405.

Garachana, M. (20I6) «Restricciones léxicas en la gramaticalización de las perífrasis verbales", RILCE. Revista de Filología Hispánica, 32.I, pp. I34-I58.

García Hernández, B. (1976) El campo semántico de «ver» en la lengua latina. Estudio estructural, Salamanca, Universidad de Salamanca. [Acta Salmanticensia, 97].

Gehrke, B. \& N. Grillo (2009) «How to become passive», dins K. K. Grohmann (ed.), Explorations of phase theory: features and arguments, Berlín, de Gruyter, pp. 23I-268.

GrÀCIA, L. (1987) «Sobre el paper temàtic dels subjectes d'alguns verb d'acció», Els Marges, 37, pp. 91-97.

Grimshaw, J. \& S. VIKNER (1993) «Obligatory adjuncts and the structure of events», dins E. Reuland \& W. Abraham (eds.), Knowledge and language II. Lexical and Conceptual Structure, Dordrecht, Springer, pp. I43-I55. 
GuÉron, J. (2008) «On the difference between telicity and perfectivity», Lingua, II8, pp. I8I6-1840 .

HaLe, K. \& S. J. Keyser (1993) «On argument structure and the lexical expression of syntactic relations", dins K. Hale \& S. J. Keyser (eds.), The view from Building 20: Essays in linguistics in honor of Sylvain Bromberger, Cambridge (Mass.), MIT Press, pp. 53-I09.

- (1997) «On the Complex nature of simple predicators», dins A. Alsina, J. Bresnan $\&$ P. Sells (eds.), Complex predicates, CSLI Lecture Notes 64, Stanford, CSLI, pp. 29-65.

- (2002) Prolegomenen to a Theory of Argument Structure, Cambridge (Mass.), MIT Press.

Halle, M. \& A. Marantz (1993) «Distributed Morphology and the Pieces of Inflection", dins K. Hale \& S. J. Keyser (eds.), The View from Building 20: Essays in linguistics in honor of Sylvain Bromberger, Cambridge (Mass.), MIT Press, pp. II-I76.

Harley, H. (2004) «Wanting, Having, and Getting: A Note on Fodor and Lepore I998", Linguistic Inquiry, 35, pp. 255-267.

- (2013). «External arguments and the Mirror Principle: On the distinctness of Voice and $v \gg$, Lingua, I25, pp. 34-57.

Harley, H. \& R. Noyer (1999) «Distributed morphology», Glot international, 4(4), pp. 3-9.

Herman, J. (2002) «La disparition du passif synthétique latin: nouvel essai sur l'écrit el le parlé en latin mérovingien», Estudis Romànics, 24, pp. 31-46.

Hernanz, M. L. \& G. Rigau (I984) «Auxiliaritat i reestructuració, Els Marges, 3I, pp. 29-5I.

JAEGGLI, O. (1986) «Passive», Linguistic Inquiry, I7, pp. 587-622.

JAQUE, M. (20I3) La expresión de la estatividad en español: niveles de representación y grados de dinamicida. [Tesi doctoral, Universidad Autónoma de Madrid.]

Jelinek, E. (1998) «Voice and Transitivity as Functional Projections in Yaqui», dins M. Butt \& W. Geuder (eds.), The projection of arguments. Lexical and compositional factors, Stanford, CSLI Publications, pp. 195-224.

KabateK, J., ed. (2008) Sintaxis histórica del español y cambio lingüistico. Nuevas perspectivas desde las Tradiciones Discursivas, Madrid/Frankfurt a. Main, Iberoamericana/Vervuert.

- (2009) "Tradiciones discursivas y cambio lingüístico», Lexis, XXIX.2 (2005), pp. I5II77. [<http://revistas.pucp.edu.pe/index.php/lexis/article/viewFile/8387/8703>.] 
Kayne, R. S. (1975) French syntax: The transformational cycle, Cambridge (Mass.), MIT Press.

Kratzer, A. (1996) «Severing the external argument from its verb», dins J. Rooryck \& L. Zaring (eds.), Phrase Structure in the Lexicon, Dordrecht, Kluwer, pp. I09-I37.

Levin, B. \& M. Rappaport Hovav (1995) Unaccusativity:Atthe syntax-lexicalsemantics interface, Cambridge (Mass.), The MIT Press.

Marantz, A. (1997) "No escape from Syntax: Don't try a morphological analysis in the privacy of your own lexicon», UPenn Working Papers in Linguistics, 4, pp. 2OI-225.

Martínez Hernández. M. (1978) Ressenya sobre B. García Hernández, «El campo semántico de "ver" en la lengua latina. Estudio estructural», Cuadernos de Filología Clásica, I5, pp. 332-337.

Massanell, M. \& J. Mateu (20I5) «A Constructional Approach to Auxiliary Selection: Evidence from Existential Constructions», dins R. Kailuweit \& M. Rosemeyer (eds.), Auxiliary Selection Revisited: Gradience and Gradualness, Berlín / Nova York, De Gruyter.

Masullo, P. J. (200I) «La transitividad como epifenómeno: el caso de los verbos de contacto", Actas del Congreso Internacional de Gramática, Buenos Aires, 1999, pp. 34-53.

Mateu, J. (2002) Argument Structure: Relational Construal at the Syntax-Semantics Interface. [Tesi doctoral, Universitat Autònoma de Barcelona. <http://webs2002. uab.es/clt/publicacions/tesis/index.html>.]

Mateu, J. \& G. Rigau (2002) «A Minimalist Account of Conflation Processes: Parametric Variation at the Lexicon-Syntax Interface», dins A. Alexiadou (ed.), Theoretical Approaches to Universals, Amsterdam, John Benjamins, pp. 2II-236.

Mateu, J. \& M. T. Espinal (2007) «Argument structure and compositionality in idiomatic constructions», The Linguistic Review, 24(I), pp. 33-59.

MendikoetXeA, A. (I999) "Construcciones inacusativas y pasivas», dins I. Bosque $\&$ V.Demonte (eds.), Gramática descriptiva de la lengua española, vol. II, pp. 1575-1629.

Muller, H. F. (1924) «The passive voice in Vulgar Latin», The Romanic Review, xv, pp. 68-93.

NapolI, M. (2013) «Semantic constraints on the Latin impersonal passive. On telicity and agentivity", dins E. van Gelderen, M. Cennamo \& J. Barodal (eds.), Argument Structure in Flux. The Naples-Capri Papers, Amsterdam, John Benjamins, pp. 373-403.

Par, A. (1923) Sintaxi catalana. Segons los escrits en prosa de Bernat Metge, Halle, Max Niemeyer. 
Pérez Saldanya, M. (2013 [ra ed. 1998]) Del llatí al català: morfosintaxi verbal històrica, Universitat de València.

Perlmutter, D. M. (1978) «Impersonal passives and the unaccusative hypothesis», dins J. Jaeger et alii (eds.), Proceedings of the Fourth Annual Meeting of the Berkeley Linguistic Society, University of California, Berkeley, pp. I57-I89.

Pinkster, H. (1990) Latin Syntax and Semantics, Londres / Nova York, Routledge.

- (1992) «The Latin Impersonal Passive», Mnemosyne, XLv, 2, pp. I59-I77.

Pustejovsky, J. (199I) «The syntax of event structure», Cognition, 4I, pp. 47-8I

Ramchand, G. (2008) Verb meaning and the lexicon: a First Phase Syntax, Cambridge, Cambridge University Press.

Ramos Alfajarín, J. R. (2000) "Ésser», «estar» $i$ «haver-hi» en català antic. Estudi sintàctic i contrastiu, València, Institut Interuniversitari de Filologia Valenciana / Publicacions de l'Abadia de Montserrat.

- (200I) «El verb haver-hi: evolució dels usos sintàctics», Estudis Romànics, XxIII, pp. I23-I46.

- (2004) «Les estructures amb «ésser» + participi passat: problemes d'ambigüitat formal», Caplletra, 36, pp. 55-72.

— (2008 [2002]) «El SV, II: La predicació no verbal obligatòria», dins J. Solà (dir.) et alii, Gramàtica del català contemporani, vol. II, cap. I4, pp. 195I-2044.

Rigau, G. (1997) «Locative sentences and related constructions in Catalan: ésser/haver alternation", dins M. Uribe-Etxebarria \& A. Mendikoetxea (eds.), Theoretical Issues at the Morphology-Syntax Interface, Bilbao, Universidad del País Vasco, pp. 395-42I. [<http://www.ehu.es/ojs/index.php/asju>.]

Rizzi, L. (1982) Italian Syntax, Dordrecht, Foris.

Roberts, I. \& A. Roussou (2003) Syntactic Change. A minimalist approach to grammaticalization, Cambridge, Cambridge University Press.

Tenny, C. L. (1994) Aspectual roles and the syntax-semantics interface, Dordrecht, Kluwer. VAn Gelderen, E. (2004) Grammaticalization as Economy, Amsterdam, John Benjamins. - (20II) The linguistic Cycle, Oxford, Oxford University Press.

Vendler, Z. (1967) Linguistics in Philosophy, Ithaca, Cornell University Press. 